\title{
Crystalline Structure, Stoichiometry and Magnetic Properties of the Morasko Meteorite
}

\author{
B. Idzikowski ${ }^{a, *}$, J. Kovác̆ $^{b}, \mathrm{P} . \mathrm{DikO}^{b}$, W.T.J. Stankowski ${ }^{c}$ And A. Muszyński ${ }^{c}$ \\ ${ }^{a}$ Institute of Molecular Physics, Polish Academy of Sciences, M. Smoluchowskiego 17, 60-179 Poznań, Poland \\ ${ }^{b}$ Institute of Experimental Physics, Slovak Academy of Sciences, Watsonova 47, 04001 Košice, Slovak Republic \\ ${ }^{c}$ Institute of Geology, Adam Mickiewicz University, Maków Polnych 16, 61-606 Poznań, Poland \\ The composition and structure of iron-nickel alloys smithereens extracted from the Morasko (Poland) \\ Meteorite (fell $\sim 5 \mathrm{ka} \mathrm{BP}$ ) were investigated by optical metallographic techniques, scanning electron microscopy \\ and electron microprobe analysis, thermal analyses, magnetic measurements and X-ray diffraction. Microstructural \\ analysis by scanning electron microscopy and optical microscopy has shown that the sample is composed from \\ large grains of $\mathrm{Fe}-\mathrm{Ni}$ alloy in which secondary phase crystals with well developed crystal habits and the size \\ about 10 micrometers are distributed. Thermal analyses confirmed that the transformation from alpha to gamma \\ $\mathrm{Fe}-\mathrm{Ni}$ solid solution appearing as a function of temperature corresponds to about $5 \mathrm{wt} \% \mathrm{Ni}$ in the $\mathrm{Fe}-\mathrm{Ni}$ alloy. \\ Possible scenario of the extraterrestrial sample solidification is related to the microstructural and magnetic behavior.
}

PACS numbers: 91.65.Sn, 75.50.Bb, 67.80.dk

\section{Introduction}

Around one tone of metallic extraterrestrial pieces of cosmic matter was found in the Morasko Meteorite Reserve (Poland) and its surrounding in about last hundred years. Moraska Góra (Morasko Hill) is the highest point in this part of Wielkopolska (Greater Poland Lowland), at around $154 \mathrm{~m}$ a.s.l. The variation of its topography is equaled by the variation in the rocks types of which inert strata and land surface is composed. At the surface more than $95 \%$ of these are Quaternary sediments of glacial and fluvioglacial origin - different in age but not younger than 18 ka BP (18000 years before present), belonging to the Poznan Stage of last glaciations. Only a small percentage of the surface consists of fine Neogene silts and clays of few millions of years old [1].

Metallic meteorites have been and still are discovered at Morasko close to the surface, normally up to the depth of $50 \mathrm{~cm}$, not deeper that around $90 \mathrm{~cm}$. It may indicate a fall of extraterrestrial matter on the surface of the ice cup and during the deglaciations located in the top part of glacigenic profiles. Practically it proved nevertheless a local impact, long time after the glacial landscape origin. Hot lamps of meteorite falling into the surface penetrated the unconsolidated Quaternary as well as Neogene sediments. The thermal influence of lamps on their immediate surroundings has been recorded in the zeroing of luminescence and creating the sinter-like coating. Later

\footnotetext{
* corresponding author; e-mail: idzi@ifmpan.poznan.pl
}

weathering resulted in the formation of a compact "meteorite skin".

The performed radiometric dating proved that the metallic extraterrestrial matter fell over a wide area around the Morasko approximately about 5000 years ago. Apart of metallic meteorites, micrometeorites and magnetic spherules are also present. An explosive impact led to the creation of meteorite craters, too.

Our earlier studies (not published yet) have shown that the meteorite is composed to about $98 \mathrm{wt} \%$ of an $(\mathrm{Fe}, \mathrm{Ni})$ -alloy and to about $2 \mathrm{wt} \%$ of $\mathrm{FeS}$ nodules, up to $20 \mathrm{~mm}$ in diameter. The latter forms the host of different trace minerals, which are likewise the carriers of many trace elements. The principal $\mathrm{Fe}-\mathrm{Ni}$ minerals are kamacite and taenite. FeS occurs as troilite, being often wrapped by rounded flakes of graphite. The trace minerals are represented by schreibersite, cohenite, sphalerite, and graphite. Additionally, tiny grains of daubreelite, altaite and silicate minerals were found, the latter being identified as the green Na-pyroxene cosmochlore (with probably composition $\mathrm{NaCrSi}_{2} \mathrm{O}_{6}$ ) and as plagioclase. Most of these trace minerals occur at the margins, but some within the troilite nodules.

\section{Experimental}

The structural composition and the microstructure of the samples was studied by analysis of X-ray diffraction (XRD) (Co $\left.K_{\alpha}\right)$ pattern, by scanning electron microscopy (SEM) and optical microscopy after polishing and etching in the solution $1 \mathrm{vol} . \%$ of hydrochloric acid in ethyl alcohol. Identification of present phases was carried 
out with using back-scattered scanning electron images and energy dispersion analysis of X-rays (EDAX).

Phase transformations during heating and cooling were studied by a differential scanning calorimeter (DSC) in flowing argon at heating and cooling rate $20^{\circ} \mathrm{C} / \mathrm{min}$. The magnetic properties were examined by vibrating sample magnetometer (VSM).

\section{Results and discussion}

\subsection{XRD analysis}

In Fig. 1 there is presented XRD pattern of sample in view. Phase analysis shown presence of bcc-(Fe,Ni) solid solution with unknown phase. The unit cell length for alpha-phase is $a=2.8735 \AA$ and was determined by XRD analysis of (211) line. According to Pearson [2], quantity of $\mathrm{Ni}$ atoms in bcc- $(\mathrm{Fe}, \mathrm{Ni})$ solid solution may be more than 5 at.\%. Quantity of Ni atoms was appreciated from comparison of measured unit cell length with FeNi solid solution values.

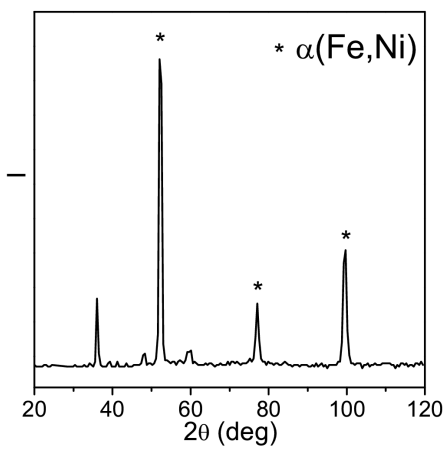

Fig. 1. XRD (Co $\left.K_{\alpha}\right)$ pattern of the meteorite sample.

\section{2. $D S C$ investigations}

In the DSC thermograms (Fig. 2) there can be seen two reversible peaks: first one under heating at $760^{\circ} \mathrm{C}$ and at about $577^{\circ} \mathrm{C}$ for cooling run, second one at $985^{\circ} \mathrm{C}$ under heating and $950{ }^{\circ} \mathrm{C}$ cooling. The first process is

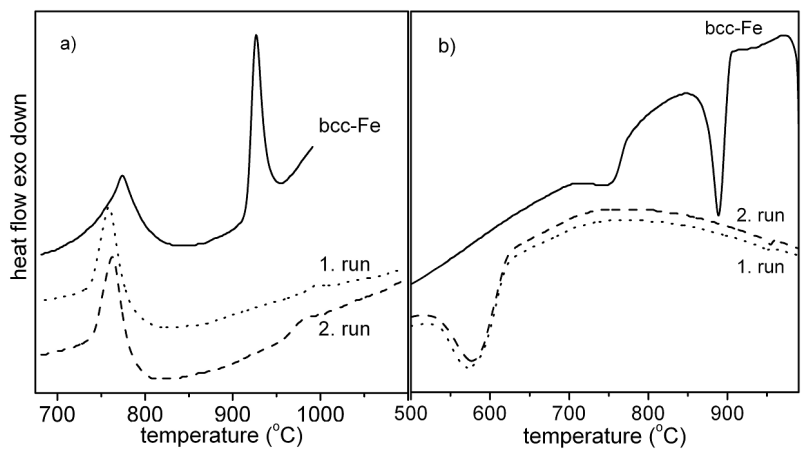

Fig. 2. DSC thermograms with heating/cooling rate $20^{\circ} \mathrm{C} /$ min.: (a) heating, (b) cooling. most probably phase transition between $\alpha \leftrightarrow \gamma$ phases. The second heat flow maxima may bring into correlation with XRD line at 36 degree, i.e. reversible transition of unknown phase with its high temperature modification.

\subsection{Microstructure}

The main body of the sample is formed by large single-phase grains (size of some millimeters). SEM observation after etching revealed that thin lamellas are present in the matrix grains (Fig. 3a,b). EDAX microanalyses

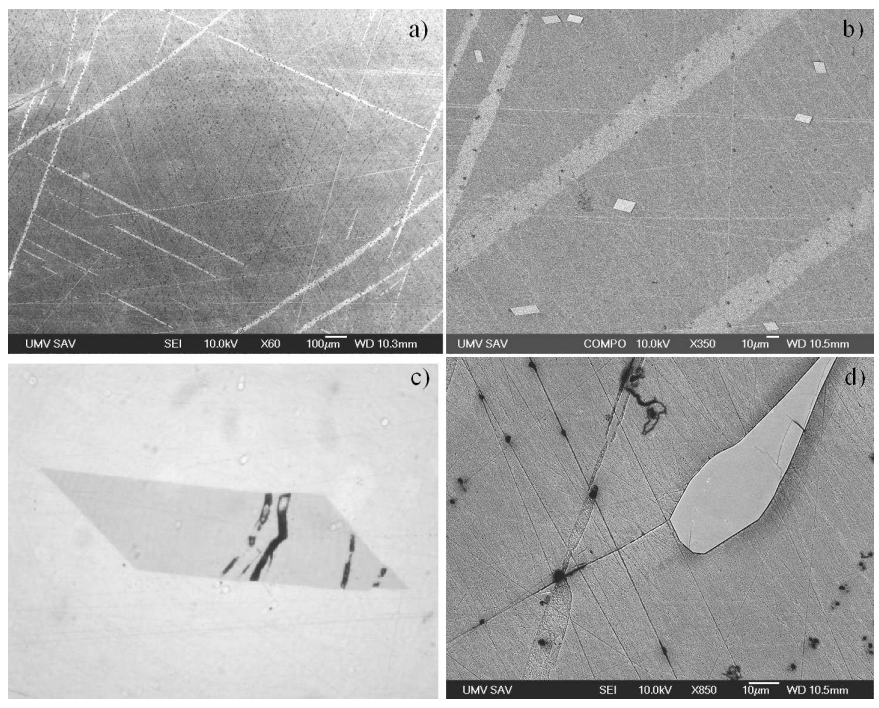

Fig. 3. Lamellas of ferrite in the austenitic grains (a) with melliniite crystals spread in the etched sample observed by SEM (b). Melliniite crystal with dark-gray part seen under plane polarized light in polished sample (c). Melliniite phase is visible at the grain boundary between austenitic grains (d).

showed that there is no difference in the composition of matrix and composition of lamellas (Table). Therefore, we suppose that these lamellas are ferrite (K8 crystal lattice) and were formed from $\mathrm{Fe} / \mathrm{Ni}$ austenite (K12 crystal lattice) during cooling through diffusionless transformation which is in agreement with the equilibrium $\mathrm{Fe} / \mathrm{Ni}$ phase diagram.

TABLE

Elemental composition of phases presented in the meteorite by EDAX analyses.

\begin{tabular}{c|c|c|c|c|c|c}
\hline \hline \multirow{2}{*}{ Phase } & \multicolumn{2}{|c|}{$\mathrm{Fe}$} & \multicolumn{2}{c|}{$\mathrm{Ni}$} & \multicolumn{2}{c}{$\mathrm{P}$} \\
\cline { 2 - 7 } & $\mathrm{wt} \%$ & at.\% & wt\% & at.\% & wt\% & at.\% \\
\hline austenite, ferrite & 93.2 & 93.6 & 6.8 & 6.2 & - & - \\
melliniite & 43.7 & 40.5 & 43.7 & 38.6 & 11.6 & 20.9
\end{tabular}

In the inner parts of the grains, some secondary phase crystals with well developed habits can be seen (Fig. 3b). The elemental microanalysis of these crystal phase particles (Table) points out that they are Fe, Ni phosphides with composition close to melliniite $(\mathrm{Ni}, \mathrm{Fe})_{4} \mathrm{P}$ [3] which 
is a new mineral found in the Northwest Africa 1054 acapulcoite meteorite in 2005.

In plane-polarized reflected light, melliniite is dark-gray (see Fig. 3c). These melliniite crystals are brittle. Observed cracks in the crystals obviously developed during sample cooling due to different thermal expansion of the $\mathrm{Fe} / \mathrm{Ni}$ matrix phase and melliniite crystals. Well developed habit planes confirm that melliniite crystals were formed in melted state e.g. the sample was formed by solidification of the melt. The melliniite phase was also observed at the $\mathrm{Fe} / \mathrm{Ni}$ grain boundaries (Fig. 3d).

\subsection{Magnetic properties}

The thermomagnetic dependences (Fig. 4a) reveal that during heating period the ferro-paramagnetic transformation occurs at $760^{\circ} \mathrm{C}$. During the cooling of sample the transformation of overcooled gamma-phase into alpha-phase arises at $615-625^{\circ} \mathrm{C}$ (inflexed point of curve).
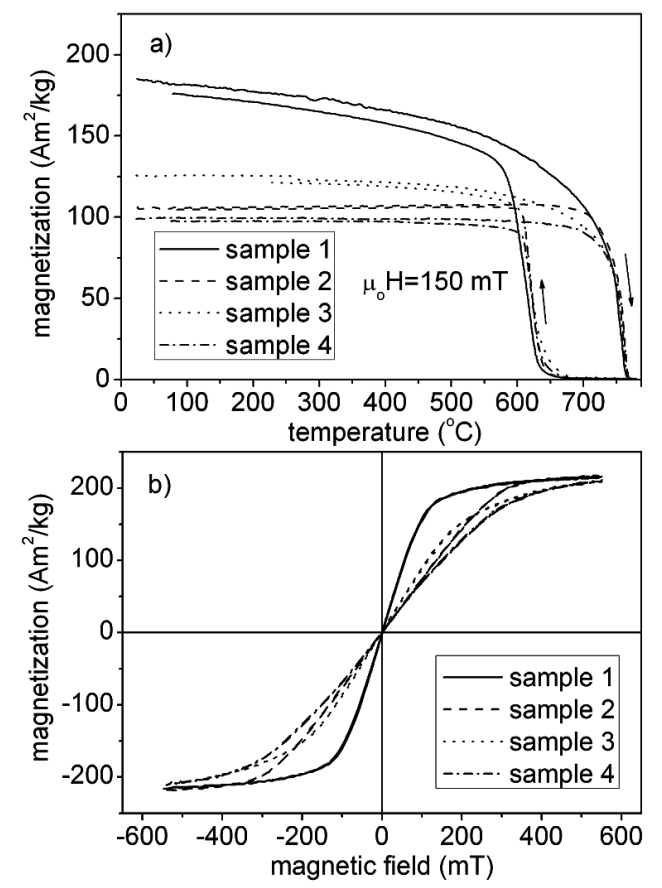

Fig. 4. Thermomagnetic dependences in magnetic field of $150 \mathrm{mT}$ (a); hysteresis loops at room temperature (b) for different meteorite samples.
These values are in good congruence with results of DSC analysis. Such type of thermomagnetic curves is usually observed in $\mathrm{Fe}, \mathrm{Ni}$ alloys with low content of $\mathrm{Ni}$ (from 1 to 10 at.\%) [4]. According to the $\mathrm{Fe} / \mathrm{Ni}$ phase diagram these temperatures answer the concentration of about 5 at.\% of $\mathrm{Ni}$ in $\mathrm{Fe}-\mathrm{Ni}$ alloy. The hysteresis loops in Fig. 4b show the different sloops represent the different crystallographic orientation of the particular samples (grains about $3 \times 3 \times 1 \mathrm{~mm}$ ) to the magnetic field.

\section{Conclusions}

The famous Polish iron meteorite Morasko, and also those found in Przełazy and Jankowo Dolne near Gniezno, probably representing a single "meteorite rain". We have confirmed in our study that the pieces of meteorite are $\mathrm{Fe}, \mathrm{Ni}$ alloy in which a very rare mineral melliniite $(\mathrm{NiFe})_{4} \mathrm{P}$ was found in the form of small particles (tens of $\mu \mathrm{m}$ ) spread in matrix of FeNi. Magnetic behavior is typical for FeNi solid solution.

\section{Acknowledgments}

This work has been supported by the Poland Ministry project "Morasko, Przełazy, Jankowo Dolne (near Gniezno) — deszcz meteorytów żelaznych" No. NN 307 3533 33, the Slovak Scientific Grant Agency (VEGA) No. 1/0311/10, project Development of Second Generation YBCO Bulk Superconductors (ITMS26220220041), which is supported by the Operational Program "Research and Development" financed through European Regional Development Fund and by VEGA project No. 2/ $0211 / 10$.

\section{References}

[1] W. Stankowski, A. Muszyński, Mater. Sci. Poland 26 (2008).

[2] W.B. Pearson, A Handbook of Lattice Spacing and Structures of Metals and Alloys, Pergamon Press, London 1958, p. 785.

[3] V. Moggi-Cecchi, L. Bindi, G. Pratesi, Meteoritics \&6 Planetary Sci 40, A105 (2005).

[4] B. Varga, J. Kováč, Mater. Sci. Forum 373-376, 275 (2001). 